\title{
First Principles Study on the Electronic Structure and Optical Property of Nd-C Codoped Anatase $\mathrm{TiO}_{2}$
}

\author{
Yi Wu ${ }^{1}$, Yan $\operatorname{Tian}^{2}$ \\ Shukai Zheng ${ }^{1,3}$
}

\author{
${ }^{1}$ Research Center for Computational Materials \& Device Simulations, College of Electronic \& Information Engineering, \\ Hebei University, Baoding 071002, P.R. China \\ ${ }^{2}$ School of Microelectronics, Xidian University, Xi' an 710071, P.R. China \\ ${ }^{3}$ Analytical Chemistry Department, Campus Universitario de Rabanales, Universidad de Córdoba, Córdoba 14071, Spain \\ e-mail: zhshk@126.com
}

\begin{abstract}
Band structures, density of states, and absorption spectra of pure, $\mathrm{Nd}$ doped, $\mathrm{C}$ doped, and $\mathrm{Nd}-\mathrm{C}$ codoped $\mathrm{TiO}_{2}$ are calculated using first-principles based on density functional theory. Calculation results show that $\mathrm{Nd}$ $4 f$ state forms empty impurity energy levels below conduction band, and C $2 p$ state together with $\mathrm{Nd} 2 f$ state forms occupied impurity energy levels with higher density than that of single doped $\mathrm{TiO}_{2}$ above valence band. Consequently, more electrons in occupied energy levels can be excited by visible light to empty $\mathrm{Nd} 4 f$ states rather than Ti $3 d$ states, resulting in further enhancement of visible light absorption and absorption edge red shift. In addition, the impurity energy levels act as carriers trap centers, thus decreasing the recombination rate of carriers.
\end{abstract}

Keywords: $\mathrm{Nd}-\mathrm{C}$ co-doping; Anatase $\mathrm{TiO}_{2}$; first-principles

\section{INTRODUCTION}

It's well known that anatase $\mathrm{TiO}_{2}$ is an excellent photocatalyst due to its nontoxicity, physical and chemical stability, low cost and high photocatalytic activity. However, anatase $\mathrm{TiO}_{2}$ has a relatively wide band $\operatorname{gap}\left(\mathrm{E}_{\mathrm{g}}=3.23 \mathrm{eV}\right)$, and only the ultraviolet light whose photon energy exceeds the band gap of $\mathrm{TiO}_{2}$ can excite photogenerated electron-hole pairs.

Furthermore, $\mathrm{TiO}_{2}$ has a high carriers recombination rate, leading to photogenerated carriers can not be made full use of. These two problems limit the wide applications of $\mathrm{TiO}_{2}$. To solve these problems, researchers made great efforts and found that doping appropriate impurities into $\mathrm{TiO}_{2}$ is an effective and practical approach to cause visible light response and reduce carriers recombination rate.

Through years of development, the dopants change from metal ions[1-7] to nonmetal ions[8-10], and the doping method develop from single doping to codoping[11-14]. Carbon is one of the most adopted nonmetal dopants both in single doping and codoping. For instance, SAKTHIVEL et al.[15] accidentally achieved $\mathrm{C}$ doped anatase $\mathrm{TiO}_{2}$ during their work on $\mathrm{N}$ doped $\mathrm{TiO}_{2}$, and found that it was much more active than $\mathrm{N}$ doped $\mathrm{TiO}_{2}$ in degradation of 4-chlorophenol with visible light irradiation. IRIE et al.[16] fabricated carbon-doped anatase $\mathrm{TiO}_{2}$ by oxidative annealing of $\mathrm{TiC}$, in which carbon atoms were at substitutional sites of oxygen atoms. Experimental results indicated that the as-prepared carbon-doped $\mathrm{TiO}_{2}$ had a smaller band gap, its absorption edge had a red shift, and showed visible light photocatalytic activity. Rare earth metal ions doped $\mathrm{TiO}_{2}$ is also one of the research focus[7,17,18]. LI et al.[19] synthesized $\mathrm{Nd}^{3+}$ doped anatase $\mathrm{TiO}_{2}$ nanoparticles, and found it being superior to undoped $\mathrm{TiO}_{2}$ nanoparticles in degrading 2-chlorophenol with visible light irradiation.

By theoretical calculations, they considered that the band gap of $\mathrm{Nd}^{3+}$ doped $\mathrm{TiO}_{2}$ was narrowed by introducing $\mathrm{Nd} 4 f$ state below the conduction band, consequently, the absorption edge shifted to visible light region. Given the important roles of $\mathrm{C}$ and $\mathrm{Nd}$ ions on the improvement of photocatalytic activity of $\mathrm{TiO}_{2}$, WU et al.[20] synthetized Nd-C codoped anatase $\mathrm{TiO}_{2}(\mathrm{C}$ at $\mathrm{O}$, and $\mathrm{Nd}$ at $\mathrm{Ti}$ ), expecting for reaching some synergetic effects between codoped ions. Their experimental results indeed indicated that $\mathrm{Nd}-\mathrm{C}$ codoped $\mathrm{TiO}_{2}$ gained further enhancement of visible light absorption compared with $\mathrm{C}$ or $\mathrm{Nd}$ alone doped $\mathrm{TiO}_{2}$, and the photogenerated carriers recombination was effectively inhibited by introduced $\mathrm{Nd} 4 f$ energy levels and 
oxygen vacancies. Therefore, the photocatalytic activity of $\mathrm{Nd}-\mathrm{C}$ codoped $\mathrm{TiO}_{2}$ was superior to single doped $\mathrm{TiO}_{2}$. By far as we know, there have no reports concentrate on the theorytical calculations of the Nd-C codoped $\mathrm{TiO}_{2}$.

So in this paper, using first principles based on density functional theory (DFT), we firstly calculated the band structures, density of states and optical absorption spectra of $\mathrm{Nd}-\mathrm{C}$ codoped $\mathrm{TiO}_{2}$. In addition, the related properties of $\mathrm{Nd}$ doped $\mathrm{TiO}_{2}, \mathrm{C}$ doped $\mathrm{TiO}_{2}$ and pure $\mathrm{TiO}_{2}$ [21] were also calculated. By comparing the electronic structures differences between $\mathrm{Nd}-\mathrm{C}$ codoped $\mathrm{TiO}_{2}$ and the pure and single doped $\mathrm{TiO}_{2}$, we investigate the mechanism of further improvement as mentioned above from the electronic structure point of view.

\section{MATERIALS AND METHODS}

In this study, $\mathrm{Nd}-\mathrm{C}$ codoped anatase $\mathrm{TiO}_{2}$ is modeled using a $3 \times 3 \times 1$ anatase $\mathrm{TiO}_{2}$ supercell, in which one $\mathrm{O}$ atom is replaced by $\mathrm{C}$ atom, and one $\mathrm{Nd}$ atom substitutes for one $\mathrm{Ti}$ atom, as shown in Figure 1. Our calculations are performed using CASTEP program[22]. The interaction between ion core and valence electrons is described by ultrasoft pseudopotential, and the Perdew-Burke-Ernzerhof (PBE) generalized gradient approximation (GGA) is employed to describe the exchange-correlation energy for valence electrons. The electron wave functions are expanded in plane wave basis set with a cutoff energy of $360 \mathrm{eV}$.

The k-points for Brillouin zone sampling is set as $2 \times 2 \times 2$. The band structure, density of states, and optical absorption spectra are calculated based on geometry optimized crystal structure. The calculations of corresponding properties of pure and single doped $\mathrm{TiO}_{2}$ are performed using the same method as that of Nd$\mathrm{C}$ codoped $\mathrm{TiO}_{2}$.

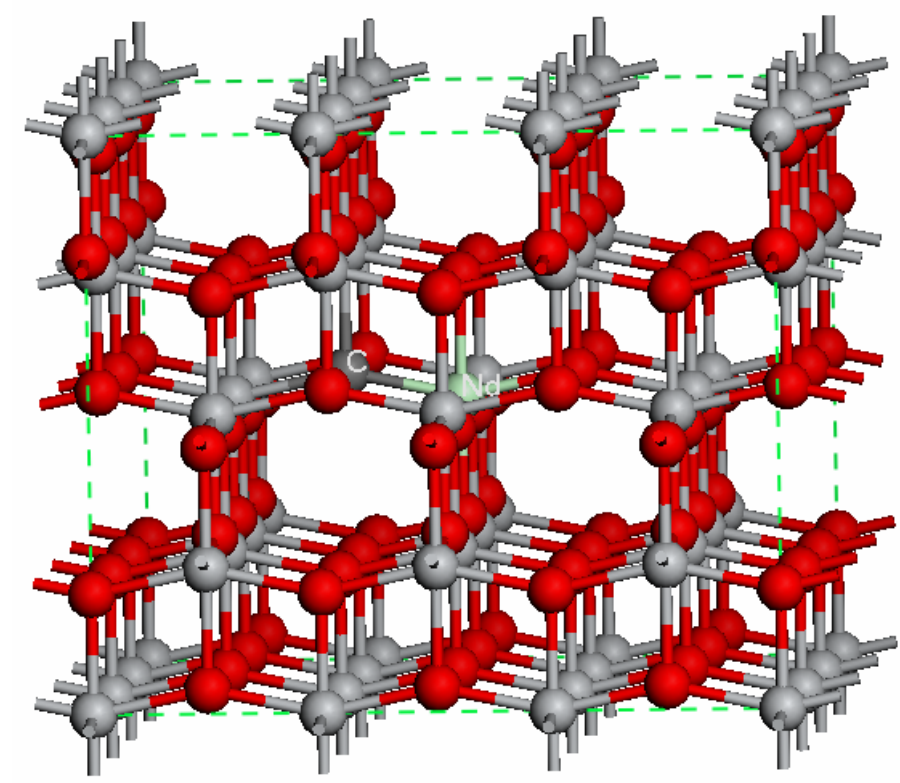

Figure 1: Structural model of Nd-C codoped $\mathrm{TiO}_{2}$

\section{RESULTS AND DISCUSSION}

The band structures and density of states (DOS) near Fermi level for pure, Nd doped, C doped, and Nd-C codoped $\mathrm{TiO}_{2}$ are shown in Figure 2. Fermi level is chosen at zero. It can be seen from Figure 2 that doping does not change band gap significantly, just gives rise to a slight band gap broadening. Therefore, the band gap is not the dominant factor which influences optical absorption. However, the dopants introduce impurity energy levels in the band gap, these gap levels can cause remarkable influence on optical absorption.

In $\mathrm{Nd}$ doped $\mathrm{TiO}_{2}, \mathrm{Nd} 4 f$ states have two density of states peaks, forming a series of intensive impurity energy levels below conduction band and an isolated energy level at Fermi level, respectively. The impurity energy levels below conduction band are above Fermi level, so they are not occupied by electrons. Electrons in valence band can absorb photons whose energy are smaller than band gap energy, and transit to the empty $\mathrm{Nd} 4 f$ state, therefore, visible light absorption of $\mathrm{Nd}$ doped $\mathrm{TiO}_{2}$ is enhanced by the introduction of $\mathrm{Nd} 4 f$ state.

Moreover, the impurity energy levels below conduction band also act as electron trap centers. Electron 
trap centers have a strong ability to capture electrons, but poor for holes. When electrons are captured by electron trap centers, holes can hardly recombine with the trapped electrons, and it takes a long time to release trapped electrons by visible light irradiation to conduction band, thus decreasing carriers recombination rate and prolonging carriers lifetime. For $\mathrm{C}$ doped $\mathrm{TiO}_{2}, \mathrm{C} 2 p$ state hybridizes with $\mathrm{O} 2 p$ and Ti $3 d$ states, forming three impurity energy levels in band gap, one is below conduction band, one is above valence band, and the other at Fermi level.

Our calculated band structure is in agreement with that of Li et al.[23] in general. The impurity energy level below conduction band lies above Fermi level, so it is lack of electrons, and the one above valence band is blow Fermi level, then is occupied by electrons. Hence, the electrons of valence band and occupied impurity energy level can be excited to conduction band and empty impurity energy level, extending optical absorption range to visible light region.

As with $\mathrm{Nd}$ doped $\mathrm{TiO}_{2}$, impurity energy levels below conduction band and above valence band play a role of electrons trap centers and holes trap centers, respectively, consequently inhibit carriers recombination and increase carriers lifetime. Nevertheless, the impurity energy level located at Fermi level is deep in band gap, and when $\mathrm{C}$ doping concentration is high enough it may become an effective carriers recombination center, this may be one reason for the existence of optimal $\mathrm{C}$ doping concentration[24].

As for $\mathrm{Nd}-\mathrm{C}$ codoped $\mathrm{TiO}_{2}, \mathrm{Nd} 4 f$ state remains two density of state peaks, the higher one is below conduction band and forms several impurity energy levels as $\mathrm{Nd}$ doped $\mathrm{TiO}_{2}$, the lower one is above valence band, together with $\mathrm{C} 2 p$ state forms an impurity energy band rather than an isolated energy level as $\mathrm{Nd}$ doped $\mathrm{TiO}_{2}$. Because the density of state peak above valence band is much bigger than that of $\mathrm{Nd}$ and $\mathrm{C}$ single doped $\mathrm{TiO}_{2}$, electrons of corresponding impurity energy levels have a larger probability to be excited to empty $\mathrm{Nd} 4 f$ and $\mathrm{Ti} 3 d$ states by visible light. In addition, electrons and holes trap centers can capture more carriers due to increase of impurity energy levels concentration, decreasing carrier recombination rate and prolonging carriers lifetime in further. As a consequence, visible light absorption and quantum efficiency of $\mathrm{Nd}-\mathrm{C}$ codoped $\mathrm{TiO}_{2}$ is enhanced compared with $\mathrm{Nd}$ and $\mathrm{C}$ single doped $\mathrm{TiO}_{2}$.
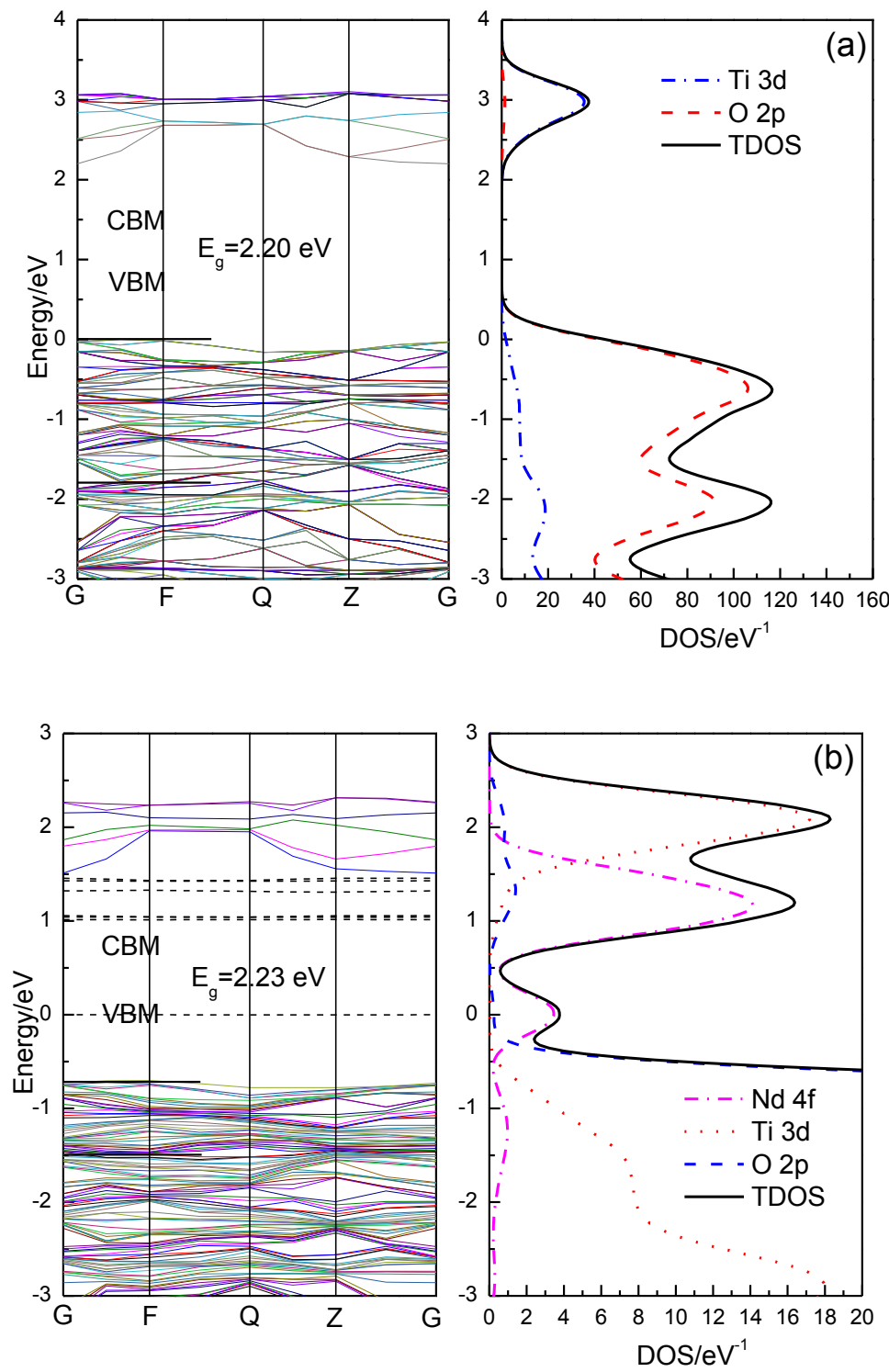

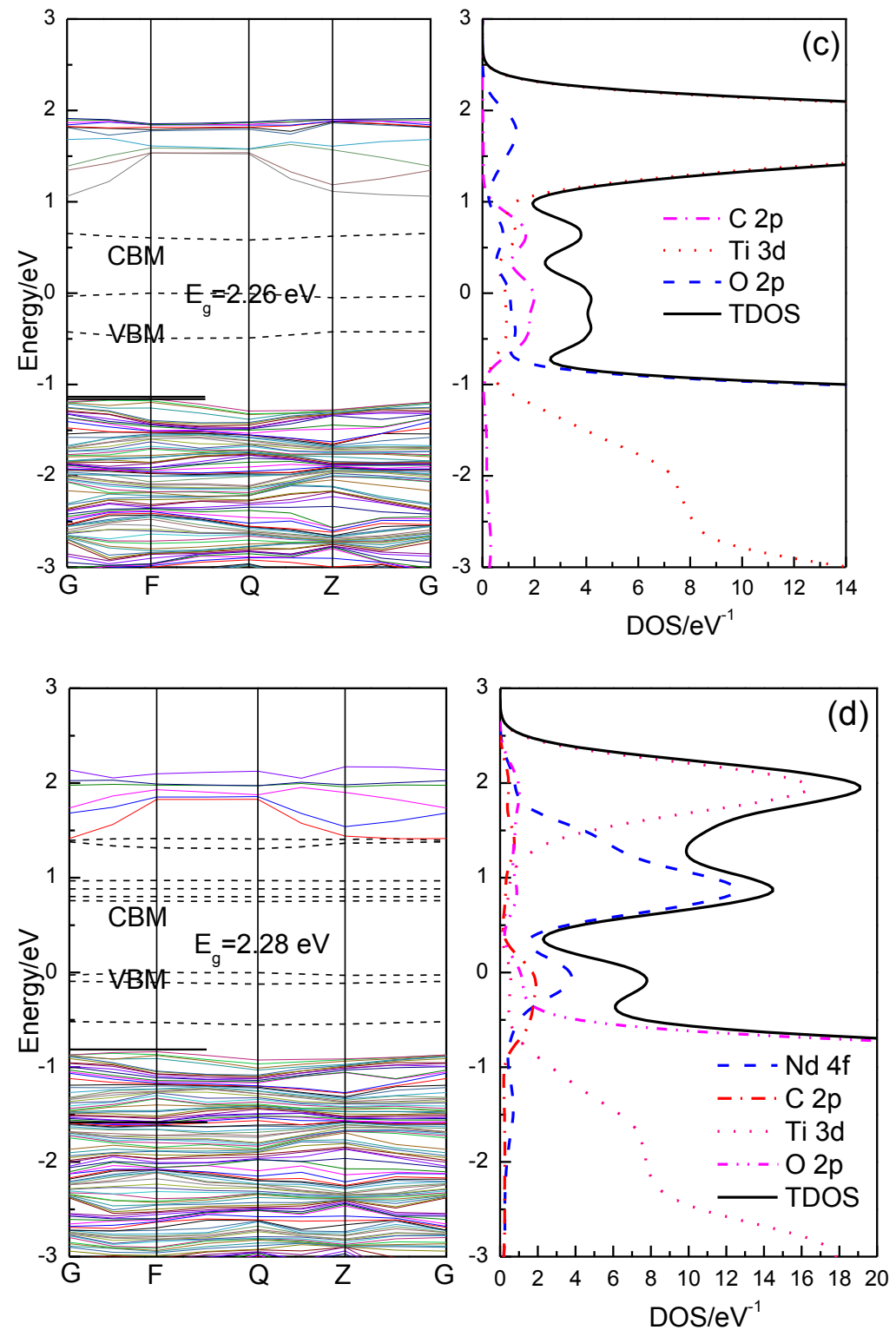

Figure 2: Structural mode Band structures and density of states for (a) pure ${ }^{[21]} \mathrm{TiO}_{2}$ (b) Nd doped $\mathrm{TiO}_{2}$ (c) $\mathrm{C}$ doped $\mathrm{TiO}_{2}$ (d) Nd-C codoped $\mathrm{TiO}_{2}$

The polycrystalline model of $\mathrm{TiO}_{2}$ was used to calculate the absorption spectra of the different systems. Because GGA method has the disadvantage of band gap underestimation, we used a "scissor operation" of $1.0 \mathrm{eV}$ to move the absorption edge of pure anatase $\mathrm{TiO}_{2}$ to $3.2 \mathrm{eV}$. The optical calculations were based on the ground state of the electrons. The calculated absorption spectra for pure, $\mathrm{Nd}$ doped, C doped, and $\mathrm{Nd}-\mathrm{C}$ codoped $\mathrm{TiO}_{2}$ are shown in Figure 3. From Figure 3 it can be seen that the absorption edge of all the doped $\mathrm{TiO}_{2}$ shifts to visible light region with respect to pure $\mathrm{TiO}_{2}$, and Nd-C codoped $\mathrm{TiO}_{2}$ has a greatest red shift extent. As all the doped $\mathrm{TiO}_{2}$ have a wider band gap than pure $\mathrm{TiO}_{2}$, the red shift should be caused by impurity energy levels. The empty impurity energy levels below conduction band form a new conduction band minimum (CBM), and the occupied impurity energy levels above valence band act as new valence band maximum (VBM), it seems like the band gap is narrowed, so the absorption edge shifts to visible light region [19]. Figure 2 also shows that $\mathrm{Nd}-\mathrm{C}$ codoped $\mathrm{TiO}_{2}$ has a more intense visible light absorption than pure and single doped $\mathrm{TiO}_{2}$, which is in agreement with experimental result [20]. 


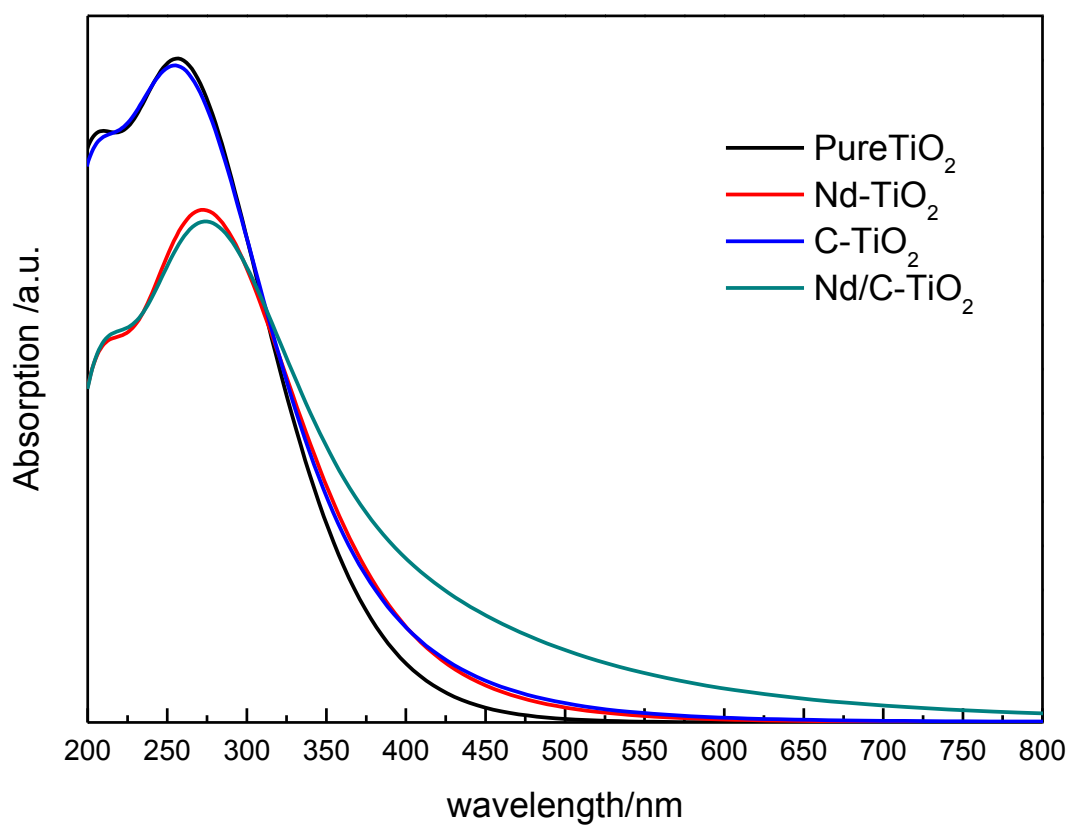

Figure 3: Absorption spectra for pure, $\mathrm{Nd}$ doped, $\mathrm{C}$ doped, and $\mathrm{Nd}-\mathrm{C}$ codoped $\mathrm{TiO}_{2}$

\section{CONCLUSIONS}

We have calculated the band structures, density of states, and absorption spectra of pure, $\mathrm{Nd}$ doped, $\mathrm{C}$ doped, and $\mathrm{Nd}-\mathrm{C}$ codoped $\mathrm{TiO}_{2}$ using first-principles based on density functional theory. $\mathrm{Nd} 4 f$ state forms empty impurity energy levels below conduction band, and C $2 p$ state together with $\mathrm{Nd} 4 f$ state forms occupied impurity energy levels with higher density than single doped $\mathrm{TiO}_{2}$ above valence band.

Consequently, more electrons in the occupied energy levels can be excited by visible light to empty $\mathrm{Nd} 4 f$ state rather than $\mathrm{Ti} 3 d$ state, resulting in further enhancement of visible light absorption and absorption edge red shift. Also, the impurity energy levels act as carriers trap centers, decreasing carriers recombination rate.

\section{ACKNOWLEDGMENTS}

The authors would like to express highly appreciation to Professor Baoting Liu at Hebei University for providing the CASTEP software and discussing the calculated results. This work is supported by the China Scholarship Council ([2014]-3012).

\section{BIBLIOGRAPHY}

[1] YU, J., XIANG, Q., ZHOU, M. "Preparation, characterization and visible-light-driven photocatalytic activity of Fe-doped titania nanorods and first-principles study for electronic structures", Applied Catalysis B Environmental, v.90, n.3, pp.595-602, Aug, 2009.

[2] YU, X., LU, Z., SI, N., et al., "Preparation of rare earth metal ion/ $\mathrm{TiO}_{2}$ Hal-conducting polymers by ions imprinting technique and its photodegradation property on tetracycline", Applied Clay Science, v.99, n.9, pp.125-130, Sep, 2014

[3] ZHANG, S., CHEN, Y., YU, Y., et al., "Synthesis, characterization of Cr-doped $\mathrm{TiO}_{2}$ nanotubes with high photocatalytic activity”, Journal of Nanoparticle Research, v.10, n.5, pp.871-875, May, 2008.

[4] CHAO, C., CHO, M, LEE, Y. “Core-shell CuO@ $\mathrm{TiO}_{2}$ nanorods as a highly stable anode material for lithium-ion batteries”, Materials Letters, v.140, n.1, pp.111-114, Feb, 2015.

[5] SONG, H.J., KIM, J.C., ROH, H.S. et al., “Anion-controlled synthesis of $\mathrm{TiO}_{2}$ nano-aggregates for $\mathrm{Li}$ ion battery electrodes", Materials Characterization, v.96, n.1, pp.13-20, Oct, 2014.

[6] ROBLES, M.J., MENDOZA, M.E., DAVILA, M.M. et al. "Influence of Ni doping on the structural, optical and textural properties of $\mathrm{TiO}_{2}$ nanocrystals prepared via an ultrasound assisted sol-gel method", Journal of Sol-Gel Science and Technology, v.69, n.3, pp.571-579, Mar, 2014. 
[7] BINGHAM, S., DAOUD, W.A., "Recent advances in making nano-sized $\mathrm{TiO}_{2}$ visible-light active through rare-earth metal doping", Journal of Materials Chemistry, v.7, n.7, pp.2041-2050, Jun, 2011.

[8] GOMATHI, D., KAVITHA, R., "A review on non metal ion doped titania for the photocatalytic degradation of organic pollutants under UV/solar light: Role of photogenerated charge carrier dynamics in enhancing the activity", Applied Catalysis B : environmental, v.140, n.8, pp.559-587, Aug, 2013.

[9] ATANELOV, J., GRUBER, C., MOHN, P., "The electronic and magnetic structure of p -element (C,N) doped rutile- $\mathrm{TiO}_{2}$ : a hybrid DFT study", Computational Materials Science, v.98, n.15, pp.42-50, Feb, 2015.

[10] HASSAN, M. E., CONG, L., LIU, G. et al., "Synthesis and characterization of C-doped $\mathrm{TiO}_{2}$ thin films for visible-light-induced photocatalytic degradation of methyl orange", Applied Surface Science, v.294, n.1, pp.89-94, Mar, 2014.

[11] CONG, Y, ZHANG, J, CHEN, F. et al., "Preparation, photocatalytic activity, and mechanism of Nano$\mathrm{TiO}_{2}$ co-doped with nitrogen and iron (III)", Journal of Physical Chemistry C, v.111, n.28, pp.10618-10623, Jun, 2007.

[12] LIU, J., HAN, R., ZHAO, Y. et al., "Enhanced photoactivity of V-N codoped $\mathrm{TiO}_{2}$ derived from a twoStep hydrothermal procedure for the degradation of PCP-Na under visible light irradiation", Journal of Physical Chemistry C, v.115, n.11, pp.4507-4515, Mar, 2011.

[13] WU, N., WANG, Y., LEI, Y. et al., "Preparation and photocatalytic activity of N-Ag co-doped $\mathrm{TiO}_{2} / \mathrm{C}$ porous ultrafine fibers mat", Ceramics International, v.40, n.1, pp.2017-2022, Jan, 2014.

[14] PATEL, N., JAISWAL, R., WARANG, T. et al., "Efficient photocatalytic degradation of organic water pollutants using V-N-codoped $\mathrm{TiO}_{2}$ thin films", Applied Catalysis B Environmental, v.150, n.1, pp.74-81, May, 2014.

[15] SAKTHIVEL, S., KISCH, H., "Daylight photocatalysis by carbon-modified titanium dioxide", Angewandte Chemie International Edition, v.42, n.40, pp.4908-4911, Oct, 2003.

[16] IRIE, H., WATANABE, Y., HASHIMOTO, K. "Carbon-doped anatase $\mathrm{TiO}_{2}$ powders as a visible-light sensitive photocatalyst”, Chemistry Letters, v.32, n.8, pp.772-773, Aug, 2003.

[17] PAN, J.W., LI, C., ZHAO, Y.F. et al., "Electronic properties of $\mathrm{TiO}_{2}$ doped with Sc, Y, La, Zr, Hf, V, $\mathrm{Nb}$ and Ta", Chemical Physics Letters, v.628, n.16, pp.43-48, May, 2015.

[18] BIAN, L., SONG, M.X., ZHOU, T.L. et al., "Band gap calculation and photo catalytic activity of rare earths doped rutile $\mathrm{TiO}_{2}$ ", Journal of Rare Earths, v.27, n.8, pp.461-468, Aug, 2009.

[19] LI, W., WANG, Y., LIN, H. et al., "Band gap tailoring of $\mathrm{Nd}^{3+}$-doped $\mathrm{TiO}_{2}$ nanoparticles", Applied Physics Letters, v.83, n.20, pp.4143-4145, Nov, 2003.

[20] WU, X., YIN, S., DONG, Q. et al., "Photocatalytic properties of Nd and C codoped $\mathrm{TiO}_{2}$ with the whole range of visible light absorption", Journal of Physical Chemistry C., v.117, n.16, pp.8345-8352, Mar, 2013.

[21] ZHENG, S.K., WU, G.H., LIU, L., "First-principles calculations on Hg-doped anatase $\mathrm{TiO}_{2}$ with and without O vacancy", Solid State Communications, v.165, n.7, pp.15-18, Jul, 2013.

[22] WANG, Y., ZHANG, R., LI, J. et al., "First-principles study on transition metal-doped anatase $\mathrm{TiO}_{2}$ ", Nanoscale Research Letters, v.9, n.4, pp.105-110, Jan, 2014.

[23] LI, N., YAO, K. L., LI, L. et al., "Effect of carbon/hydrogen species incorporation on electronic structure of anatase-TiO ${ }_{2}$ ", Journal of Applied Physics, v.110, n.7, pp.073513-073513, May, 2011.

[24] WONG, M. S., HSU, S.W., RAO, K.K. et al., "Influence of crystallinity and carbon content on visible light photocatalysis of carbon doped titania thin films", Journal of Molecular Catalysis A Chemical, v.279, n.1, pp.20-26, Jan. 2008. 